\title{
THE INFLUENCE OF THE CUBOID FLOAT'S PARAMETERS ON THE STABILITY OF A FLOATING BUILDING
}

\author{
Artur Karczewski ${ }^{1}$ \\ Lukasz Piątek ${ }^{2}$ \\ ${ }^{1}$ Gdańsk University of Technology, Poland \\ ${ }^{2}$ Warsaw University of Technology Department of Architectural and Urban Design, Poland
}

\begin{abstract}
Usually, the concept of sufficient stability of a floating structure is connected with the capacity to keep a small heel angle despite the moment of heeling. The variable responsible for these characteristics is the initial metacentric height, which is the relation between the hydrostatic features of the pontoon and the mass properties of the entire object. This article answers the questions of how heavy the floating system should be, what the minimum acceptable draft is, and whether it is beneficial to use internal fixed ballast. To cover various technologies, a theoretical model of a cuboid float with average density representing different construction materials was analysed. The results indicate that the common practice of using heavy and deep floating systems is not always reasonable. In the case of floating buildings, which, unlike ships, can be exploited only under small heel angles, the shape and width of the submerged part of the object may influence the stability more than the weight or draft.
\end{abstract}

Keywords: floating buildings, floating houses, houseboats, stability, floating body

\section{INTRODUCTION}

The tradition of building at the interface between land and water using various kinds of floating objects that derive from water vessels goes back to antiquity [22]. In the twentieth century in Western Europe and North America, new construction technology allowed traditional rafts and ship hulls to be replaced with floating systems built of waterproof concrete and extruded polystyrene [5]. Modern floating buildings were born and started to grow in number.

Nowadays, there are around 40-50 thousand stationary floating structures of various kinds around the world, excluding those that incorporate any kind of watercraft, like houseboats [6]. Contemporary floating buildings using various materials and technologies developed for floating platforms such as wood, steel, aluminium, reinforced concrete, fibreglass, and plastics [21] have already proven to be safe and reliable building constructions. They are gaining attention as a potential solution to the problem of sea-level rise [10] and due to their sustainability [13], [9]. This growth trend is very strong in countries where floating development became popular only in the twenty-first century [16]. However, not much effort has been made toward the scientific exploration of the stability analysis of floating buildings.

Once in the water, the floating object has to sustain different environmental conditions: wind and water pressure, snow weight, ice, and waves. A separate group of loads to be considered is shock loads due to vibration, impacts, accelerations, or inertia. Depending on the properties of the construction materials, the problems of thermal expansion, water-absorbability, and corrosion must be considered in the long term. Finally, the variable live loads must be included. Thus, it is of utmost importance for such an object occupied by people - such as a ship, floating offshore structure, or floating house - to remain safe and afloat in all conditions. Especially in the case of waterbased facilities for users who do not have special training, the stability of floating objects is one of the most important factors that influence the safety and comfort onboard. 
Tab. 1 Freeboard and heel angle requirements according to different guidelines

\begin{tabular}{|c|c|c|c|c|}
\hline \multirow[t]{2}{*}{ Title } & \multirow[t]{2}{*}{ Region } & $\begin{array}{l}\text { Min. freeboard, } \\
\mathrm{Fb}\end{array}$ & $\begin{array}{l}\text { Max. heel } \\
\text { angle }\end{array}$ & $\begin{array}{l}\text { Min. residual } \\
\text { freeboard }\end{array}$ \\
\hline & & {$[\mathrm{m}]$} & {$\left[{ }^{\circ}\right]$} & {$[\mathrm{m}]$} \\
\hline Building Code for Float Homes [2] & Alaska, USA & $0.36(14 ”)$ & 4 & $1 / 2 \mathrm{Fb}$ \\
\hline $\begin{array}{l}\text { Regulation of the Construction and Maintenance of Floating } \\
\text { Homes [7] }\end{array}$ & California, USA & $0.38\left(15^{\prime}\right)$ & 4 & $1 / 3 \mathrm{Fb}$ \\
\hline British Columbia Float Home Standard [1] & $\begin{array}{l}\text { British Columbia, } \\
\text { Canada }\end{array}$ & 0.40 & 5 & $1 / 2 \mathrm{Fb}$ \\
\hline $\begin{array}{c}\text { Technical Regulation on the Stability, Buoyancy, etc. of } \\
\text { Houseboats and Floating Structures [3] }\end{array}$ & Denmark & 0.50 & 4 & $1 / 3 \mathrm{Fb}$ \\
\hline Queensland Development Code. MP 3.1 Floating Buildings [4] & Queensland, Australia & 0.40 & - & 0.25 \\
\hline NTA 8111 Drijvende bouwwerken [Floating constructions] [11] & Netherlands & 0.00 or 0.30 & 4 & 0.00 or 0.30 \\
\hline $\begin{array}{l}\text { AS 3962-2001 The Australian Standard: Guidelines for Design } \\
\text { of Marinas [20] }\end{array}$ & Australia & - & 15 & 0.05 \\
\hline $\begin{array}{c}\text { PN-EN 14504: } 2010 \text { Inland navigation vessels - Floating } \\
\text { landing stages and floating bridges on inland waters - } \\
\text { Requirements, tests [17- }\end{array}$ & $\mathrm{EC}$ & 0.03 & 10 & - \\
\hline Guidelines for Floating Platforms for Yacht Marinas [8] & Poland & 0.05 & 6 & - \\
\hline
\end{tabular}

In terms of engineering, stability analysis evaluates a floating object when heeled from equilibrium by external forces and determines its capability to sustain them by finding a new position of balance. An object can be considered safe if it retains its ability to return to its original position after cessation of the heeling forces. Insufficient stability can lead to flooding of the object, destruction of its elements, or even sinking.

Generally, there is a consensus in academia and industry about the assessment of the ship's stability. This problem can be divided into two issues: the initial stability at so-called 'small heel angles' (smaller than the deck immersion angle) and stability at large heel angles (over 25 degrees) [15] when the ship's safety after the deck immersion is being checked. Heel angles of less than 6 degrees are not taken into consideration, as they overlap with the period of ship's own sway. Stability criteria for ships are strongly connected with the ships geometry (high freeboard and a large reserve of hull volume) based on their function.

Floating buildings have different operational conditions and geometric characteristics. Unlike ships, they are located on calm or sheltered waters, allowing them to have relatively low freeboards, which are very convenient for marina or swimming facilities. On the other hand, they are used and equipped like buildings (e.g., they have movable furniture inside). For these reasons, a heel angle of over 10 degrees or immersion of the deck would pose a danger to the people onboard. Therefore, the stability criteria introduced for ships cannot be directly applied to floating buildings. This difference is visible in various local guidelines and regulations on the stability of stationary floating objects (Table 1), requiring a smaller heel angle and larger residual freeboard than the criteria for ships. However, in terms of stability, floating buildings are often confused with ships. A common habit of associating a heavy and deep floating system with improving stability is an example of this problem.

For these reasons, this article focuses on the problem of the impact of the flotation type on the stability, which has to be examined for 'very small angles of heel', meaning angles smaller than 10 degrees. This issue was not previously considered, probably due to its apparent triviality or lack of usefulness for the shipping industry. But for floating buildings, it is an essential safety consideration.

According to theory [18], [19], the stability characteristics at small angles of heel are correlated with the initial metacentric height $G M$ defined by the equation'

$$
G M=\frac{T}{2}+\frac{B^{2}}{12 \cdot T}-V C G
$$

where $T$ is the draft [m], $B$ is the breadth [m], and VCG is the vertical height of the object's centre of gravity [m].

It is clear that the GM and initial stability will be increased by enlarging the breadth and lowering the centre of gravity. The latter may suggest the advantage of heavy floating systems. But the relation of VCG to $T$ is complex because these factors are indirectly connected with many other parameters not visible in Eq. (1). For example, adding ballast to the existing building would lower its centre of gravity and increase the draft at the same time. Therefore, formulating simple guidelines based on the interpretation of the simplified GM formula is difficult.

\section{METHODS - STABILITY EVALUATION}

The initial research question is whether heavy and deep floating systems can increase the stability of floating buildings at heel angles of up to 10 degrees. To examine this issue in an exploratory way, three scenarios of changes in the basic parameters of the floating system were determined:

(1) increasing the weight (density);

(2)increasing the depth;

(3) increasing both the weight and depth in such relation that the freeboard does not change.

1 Provided that the heeling of the object free-floating on the calm water is due to the effect of the static force of wind and the shape of the submerged part of the floating body is cuboid. 
To assess the relative influence of the weight and $\mathrm{draft}$ on stability, all research scenarios were conducted for two numerical models of theoretical floating structures having different breadths. Both objects consisted of a cuboid floating system (flotation device, float) and an open superstructure. In simplification, the upper part inflicts loads (gravity and wind pressure), while the lower part generates the reaction (buoyancy and righting moment) in the system. The selected parameters of the floating system were subject to change, whereas the parameters of the superstructure were constant (Table 2).

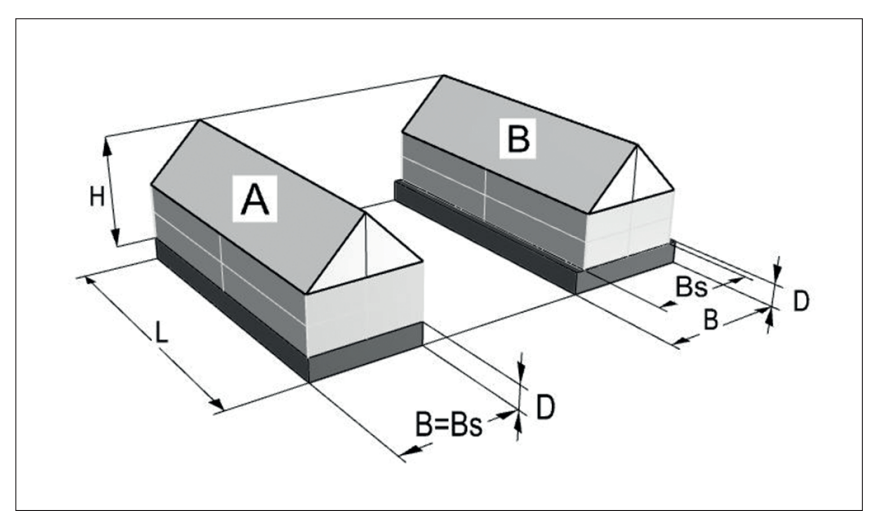

Fig. 1 Main dimensions of examined objects

Table 2 General constant characteristics of examined models

\begin{tabular}{|c|c|c|c|}
\hline \multicolumn{2}{|c|}{ Model } & \multirow{2}{*}{ A } & B \\
\cline { 1 - 2 } Characteristic & Symbol & \multicolumn{2}{|c|}{16.0} \\
\hline Float and superstructure length & $L[\mathrm{~m}]$ & 6.0 & 7.0 \\
\hline Float breadth & $B[\mathrm{~m}]$ & \multicolumn{2}{|c|}{6.0} \\
\hline Superstructure height & $H[\mathrm{~m}]$ & \multicolumn{2}{|c|}{6.0} \\
\hline Superstructure breadth & $B_{S}[\mathrm{~m}]$ & \multicolumn{2}{|c|}{75} \\
\hline Superstructure density & $\begin{array}{c}q_{S}[\mathrm{~kg} / \\
\left.\mathrm{m}^{3}\right]\end{array}$ & \multicolumn{2}{|c|}{75} \\
\hline
\end{tabular}

In the numerical simulation, the stability of two models was computed according to simplified formulas for angles in which the side of the floating system was not entirely submerged:

$$
\varphi=\frac{M_{H}}{m \cdot g \cdot G M}
$$

where $\varphi$ is the heel angle $\left[^{\circ}\right], M_{H}$ is the heeling moment $[\mathrm{Nm}]$, $m$ is the mass of the object $[\mathrm{kg}], g$ is $9.81\left[\mathrm{~m} / \mathrm{s}^{2}\right]$, and

$$
F b_{\varphi}=\cos \varphi(D-T-\operatorname{tg} \varphi \cdot 0.5 \cdot B)
$$

where is the residual freeboard [m], is the depth of the floating system [m], and:

$$
M_{H}=q \cdot A_{w} \cdot(D+0.5 \cdot(H-T))
$$

where $q$ is wind pressure $[\mathrm{Pa}]$, and $A_{w}$ is the area of side surface exposed to wind $\left[\mathrm{m}^{2}\right]$.
To simplify the problem, no live loads were taken into consideration in the simulations. Reducing the problem of stability to the response to the high wind pressure acting perpendicular to the longer wall can be justified by the relatively higher impact of this factor on the stability as well as its independence from the breadth of the float. Therefore it was assumed to be acceptable in the theoretical study investigating the relationship between the characteristics of the floating system and stability. To achieve a significant change in the observed parameters, a relatively high wind pressure $(600 \mathrm{~Pa})$ was introduced. This configuration corresponds to the requirements for the assessment of floating scaffoldings set in [18].

\section{RESULTS}

The results of the above simulations are presented in Figs. 2-4. In each figure, there is a chart showing the heel angle (dashed line) and residual freeboard (solid line) for both model A (red lines) and model B (green lines). Under the charts, the change of the metacentric height is presented on the model A sections (where $M$ is the metacentre, $G$ is the centre of gravity, and $F$ is the centre of buoyancy). ${ }^{2}$

\section{INCREASING THE WEIGHT OF THE FLOAT (FIG. 2)}

In this case, the density of the floating system $q$ was increased from $50 \mathrm{~kg} / \mathrm{m}^{3}$ (value representative for steel pontoon) to $550 \mathrm{~kg} / \mathrm{m}^{3}$ (heavy-duty reinforced concrete float). To a certain extent, this scenario represents placing fixed ballast inside the floating system as well.

As a result:

(1) The heel angle decreased. This has to do with the fact that as the mass of the object increases, the righting moment also increases because it is the product of the mass and righting arm. The advantage of adding the mass is not as large as one would have expected (less than 2 degrees improvement in heel angle for model A). This is because there is a decrease in metacentric height at the same time due to the increase in the draft. For a wider model $\mathrm{B}$, the difference between a light and a heavy float is particularly small.

(2) The residual freeboard decreased rapidly. As the weight increases, the freeboard is reduced in favour of the draft. This seems obvious, as the float has a limited reserve of volume. For this reason, it is easy to predict that there is always a limit of mass for a given size of the floating system, and, after exceeding it, the criterion of residual freeboard will not be met.

(3) The metacentric height decreased. A heavier floating system shifts the centre of gravity downwards. However, neither the increase in the height of the buoyancy centre nor the decrease in the centre of gravity prevents a decrease in the metacentric height. Therefore, the object with a heavier float has lower initial stability.

2 The tendency of the change in the metacentre is the same for model $\mathrm{A}$ and model $\mathrm{B}$. 


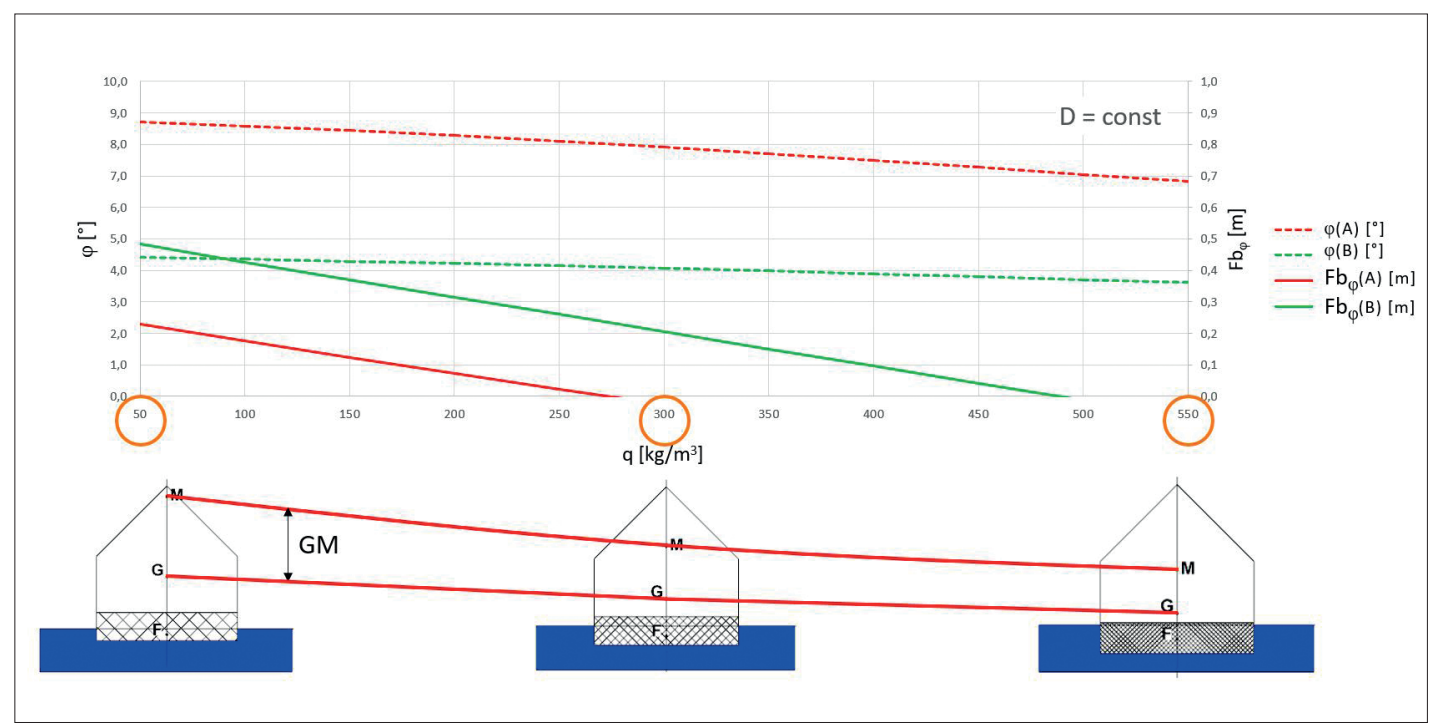

Fig. 2 Increasing the density of the floating system

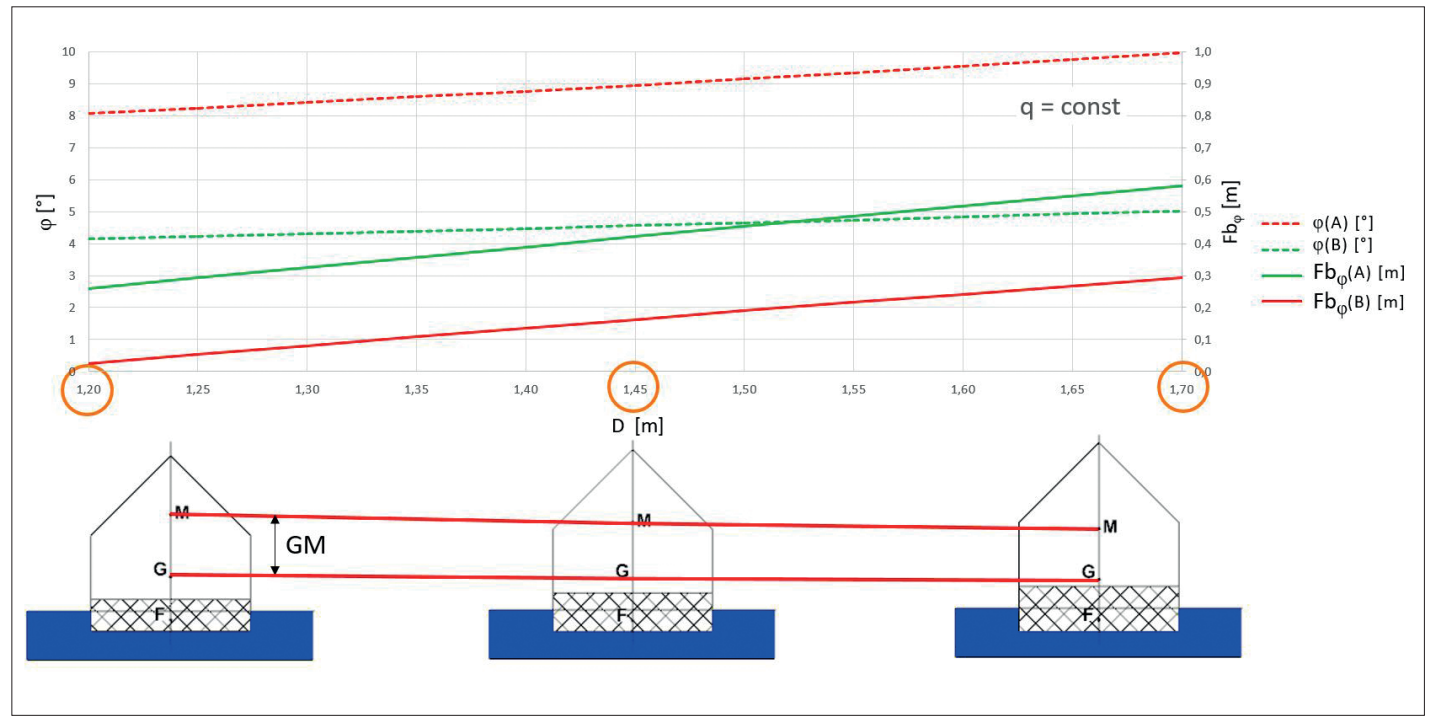

Fig. 3 Increasing the depth of the floating system

\section{INCREASING THE DEPTH OF THE FLOAT (FIG. 3)}

In the second scenario, the depth of the floating system $D$ was increased from 1.2 to $1.7 \mathrm{~m}$, while its density $q$ was constantly equal to $275 \mathrm{~kg} / \mathrm{m}^{3}$ (average value for different materials).

As a result:

(1) The heel angle increased. The density of the floating system is four times smaller than the density of water, so the volume reserve is larger for the higher floats. The float emerges from the water, which increases the wind profile and the heeling moment. As a result, the heel angle increased by about 2 degrees for model $A$ and 1 degree for model $\mathrm{B}$.

(2) The residual freeboard increased. As the deck moves away from the water, the deck flooding angle increases. However, the design solution can be unacceptable, as in an upright position the deck may be too high above the water surface, which is contradictory to architects' ideas and users' expectations [12].

(3) The metacentric height did not change significantly. The influences of mass properties, such as the height of the centre of gravity, and hydrostatic characteristics, such as draft, balanced each other out.

\section{INCREASING THE DENSITY AND THE DEPTH OF THE FLOAT WITHOUT AFFECTING THE FREEBOARD (FIG. 4)}

In the last scenario, both parameters were increased (the density from 50 to $550 \mathrm{~kg} / \mathrm{m}^{3}$ and the depth from 1.06 to $2.11 \mathrm{~m}$ ) in such proportion that the freeboard in the upright position remained unaffected. It required an additional calculation of the float height corresponding with a linear increase in the weight of the floating system. This scenario is highly probable in floating-building designs, where a fixed 


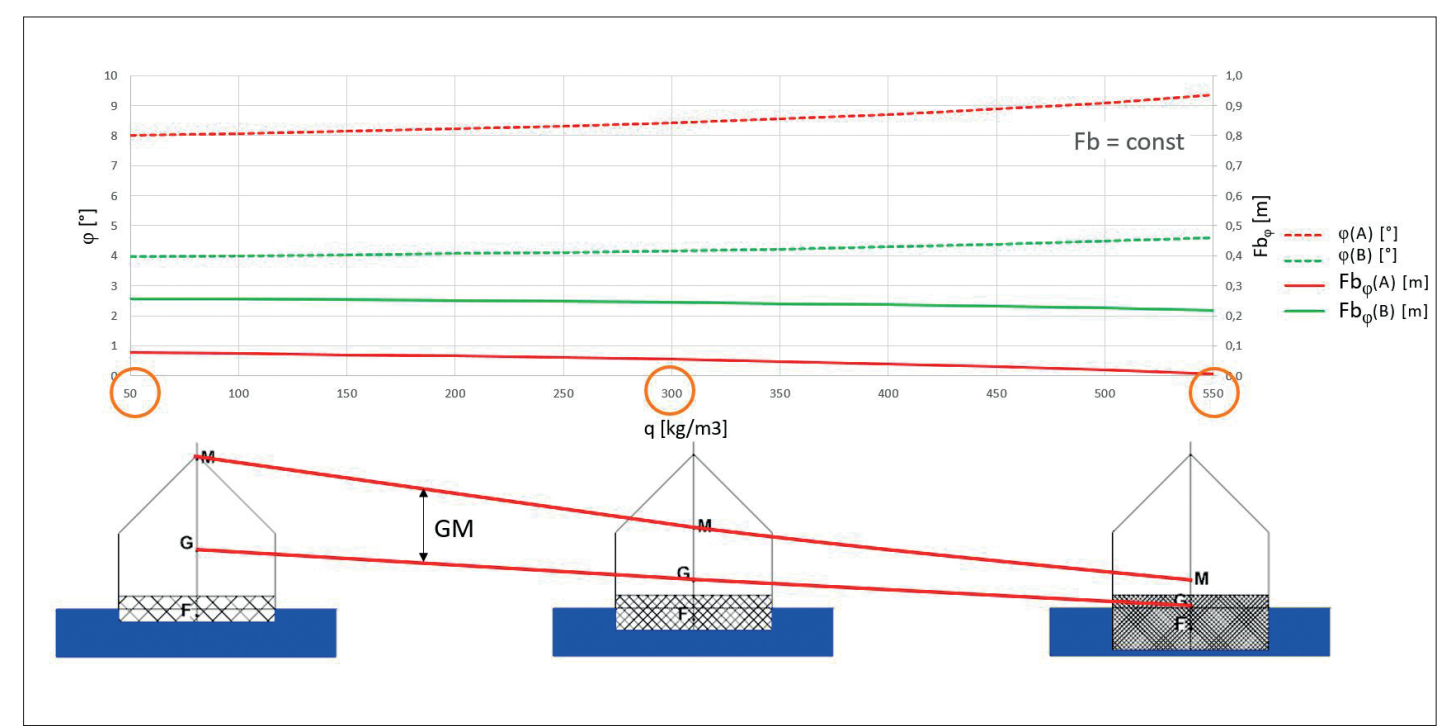

Fig. 4 Increase of weight and depth of floating system without affecting the freeboard

freeboard height is one of the main initial assumptions resulting from specific land access conditions.

As a result:

(1) The heel angle increased. Similarly to the second scenario, the changes are in the range of 1-2 degrees. The wider model B is less susceptible to change. In Eq. (2), the breadth is in the square, so for the assumed dimensions of floats, it gives about a $36 \%$ reserve in this parameter for all changes.

(2) The residual freeboard decreased. Although in both cases the decrease in the whole examined spectrum was only a few centimetres, it may become crucial for meeting the stability criteria.

(3) The metacentric height decreased. The submerged part of the structure increases in volume while maintaining a constant shape and area of waterplane. Therefore, the metacentric height decreases very fast. The increase in float depth plays a major role. Theoretically, even though the increase of heel angle and decrease of residual freeboard are small, the final stability properties are worse for the heavy and deep floating system than for a lightweight and shallow one.

\section{DISCUSSION}

This article discusses the stability of a floating building that has a relatively low draft, intended for very shallow waters or suitable for one-story structures. This problem has not been investigated before, probably due to its seeming triviality or the relatively low popularity of low-draft floating buildings. Despite that, lightweight floating buildings are gaining more and more attention [14].

There are many reasons why the introduction of different, heavy, and deep floating systems may be required, such as a large weight of the multi-story superstructure, high live load, or the demand for underwater usable space in the hull.
It has to be said that the dynamics of the movement may be more important for the structure's safety and comfort than the maximum heel angle. Therefore, heavier floats having higher inertia may be suitable for places with higher waves or gusty winds, as long as they meet the stability criteria.

Another issue is the problem of the additional reserve of stability that may be required for a floating building in extreme wind conditions. Even in such cases, after evacuating people ashore, the structure should remain stable at larger heel angles than 10 degrees and must not capsize. This may require a float that is deep (to maintain the deck over the water and the bilge under the water) and heavy (to balance a higher heeling moment in extreme winds).

In all cases, it is beneficial to design a lightweight superstructure, as it lowers the centre of gravity and increases the freeboard at the same time.

\section{CONCLUSIONS}

Intuitive solutions are not always suitable. Research shows that increasing the weight of a floating system (including adding fixed ballast) does not improve stability in a significant way but does have a large influence on the residual freeboard. On the other hand, increasing the depth of the floating system improves safety because it is safe from flooding. However, the utility of the building decreases as the freeboard is too high in the upright position. In all examined scenarios, enlarging the breadth of the floating system resulted in a far better improvement of the stability. Increasing the beam decreases the heel angle, which in turn increases the residual freeboard.

An additional important conclusion is that there is no simple way in which the stability can be improved after the construction phase starts because, usually, maintaining the freeboard in an upright position is the utility constraint and there is no reserve there. Design errors revealed at this stage may become very difficult or even impossible to correct, unless some additional buoyancy is added to the floating system 
or the superstructure is redesigned to be lighter. Therefore, a precise design, including weight and stability calculations that will be carefully followed, is crucial. It is particularly important in the case of narrow or high floating structures.

\section{REFERENCES}

1. B.C. Building Code (2003): British Columbia Float Home Standard.

2. City and Borough of Sitka, Alaska. (2019): Home Rule Charter of the City and Borough of Sitka. Chapter 19.15 Building Code for Float Homes.

3. Danish Maritime Authority. (2007): Technical Regulation on the Stability, Buoyancy, etc. of Houseboats and Floating Structures. Retrieved from https://www.dma.dk/Vaekst/ Rammevilkaar/Legislation/Pages/Technical-regulations. aspx.

4. Department of Housing and Public Works. (2007): Queensland Development Code. MP 3.1 Floating Buildings. Retrieved from http://www.hpw.qld.gov.au/construction/BuildingPlumbing/ Building/BuildingLawsCodes/QueenslandDevelopmentCode/ Pages/QueenslandDevelopmentCodeCurrentParts.aspx.

5. Flanagan B. (2003): The Houseboat Book. Universe, New York.

6. Holcombe S. (2017): Applications and Huge Potential Demand for Amphibious Structures. Proceedings of the First International Conference on Amphibious Architecture, Design \& Engineering, 138.

7. Marin County, California. (2016): California Municipal Code. Chapter 19.18. Regulation of the Construction and Maintenance of Floating Homes.

8. Mazurkiewicz B. (2010): Yacht Harbors and Marinas. Designing. Foundation for the Promotion of Industry Shipbuilding and Maritime Economy, Gdańsk.

9. Moon C. (2014): Three Dimensions of Sustainability and Floating Architecture. International Journal of Sustainable Building Technology and Urban Development, Vol. 2, 123-127.

10. Nakajima T., Umeyama M. (2015): A New Concept for the Safety of Low-lying Land Areas from Natural Disasters. Journal of Ocean Engineering and Marine Energy, Vol. 1, 19-29.

11. Nederlands Normalisatie-Instituut (2011): NTA 8111 Drijvende Bouwwerken [Floating Constructions]. NEN, Delft.

12. Nillesen A. L., Singelenberg J. (2011): Amphibious Housing in the Netherlands. Architecture and Urbanism on The Water. NAI, Rotterdam.
13. Olthuis K., Keuning D. (2011): Float! Building on Water to Combat Urban Congestion and Climate Change. Frame, Amsterdam, 204-231

14. Ostrowska-Wawryniuk K., Piątek Ł. (2020): Lightweight Prefabricated Floating Buildings for Shallow Inland Waters. Design and Construction of The Floating Hotel Apartment in Poland. Journal of Water and Land Development, Vol. 44 (I-III) , 118-125.

15. Papanikolaou, A. (2014): Ship Design, Methodologies of Preliminary Design. Springer; London.

16. Piątek Ł. (2018): Architecture of Floating Buildings: Conditions and Directions of Development in Poland after 2000. PhD Thesis, Warsaw University of Technology.

17. Polish Committee for Standardization (2019): PN-EN 14504: 2010 Inland navigation vessels - Floating landing stages and floating bridges on inland waters - Requirements, tests. Warsaw.

18. Polish Register of Shipping (2019): Rules for Classification and Construction of Inland Waterways Vessels, Part IV, Stability and Freeboard. Gdańsk.

19. Rawson, K. J., Tupper, E. C. (2001): Basic Ship Theory, v. 1, Hydrostatics and Strength. 5th Edition, Butterworth Heinemann. Oxford.

20. Standards Australia (2001): AS 3962-2001 The Australian Standard: Guidelines for Design of Marinas. Sydney.

21. Szymczak-Graczyk A. (2018): Floating platforms made of monolithic closed rectangular tanks. Bulletin of the Polish Academy of Sciences: Technical Sciences, 2, Vol. 66, 209-219.

22. Wang C. M., Wang B. T. (2014): Great Ideas Float on the Top. Large Floating Structures: Technological Advances. Springer, $1-36$.

\section{CONTACT WITH THE AUTHORS}

\section{Artur Karczewski}

e-mail:artkarcz@pg.gda.pl

Gdańsk University of Technology

11/12 Gabriela Narutowicza Street, 80-233 Gdańsk

$$
\text { Poland }
$$

\section{Lukasz Piątek}

e-mail: lukasz.piatek@pw.edu.pl

Warsaw University of Technology

Department of Architectural and Urban Design

Pl. Politechniki 1, 00-661 Warszawa

Poland 